\title{
Status and Challenges in Implementing Beyond Budgeting: Evidence from Sri Lanka
}

\author{
Dileepa N. Samudrage ${ }^{1}$, Hansinee S. Beddage ${ }^{1}$ \\ ${ }^{1}$ Faculty of Management Studies and Commerce, University of Sri Jayewardenepura, Nugegoda, Sri Lanka \\ Correspondence: Dileepa N. Samudrage, Faculty of Management Studies and Commerce, University of Sri \\ Jayewardenepura, Nugegoda, Sri Lanka.
}

Received: November 2, 2018

Online Published: November 29, 2018

doi:10.5539/ibr.v11n12p113

URL: https://doi.org/10.5539/ibr.v11n12p113

\begin{abstract}
Due to the weaknesses of Traditional Budgeting and Better Budgeting, budgeting moved to its third wave called Beyond Budgeting. Beyond Budgeting is an alternative, coherent management model that enables companies to manage performance through processes specifically tailored to suit today's volatile market.

Although, researchers have explained how organisations should move to Beyond Budgeting they have not discussed as to why some organisations are lagging behind in terms of Beyond Budgeting implementation. Therefore, this study intends to address and bridge the above research gap. Specifically, the study investigates how far the existing organizational set-ups support an advanced model called Beyond Budgeting and explores why can or cannot these organisations move to Beyond Budgeting.

The study carries out a multiple case study approach because it provides an in-depth analysis of budgetary processes of four reputed Sri Lankan companies. Data was collected through semi-structured interviews and documentation reviews where data triangulation was used to validate the data.

Based on the findings the study concluded that in the existing organizational set-ups, leadership principles of Beyond Budgeting were strongly present compared to process principles. It was also found that complications in setting rolling forecasts, bureaucracy, lack of virtues, dependency culture on budgets to evaluate performance, perceiving dynamic goals as too ambiguous to set and lack of competitor intelligence as main barriers of moving to Beyond Budgeting concept.
\end{abstract}

Keywords: traditional budgeting, Beyond Budgeting, leadership principles, process principles, Sri Lanka

\section{Introduction}

Budgeting is one of the most frequently used managerial tools by any organization. Also, it is a tool that has been repeatedly researched on. Budget is understood by many scholars as a device for planning and controlling the performance and output in organisations (Rickards, 2008; Chong et al., 2005; Anthony, 1965; Frow et al., 2010, Ekholm \& Wallin, 2000; Niels \& Per, 2014).

However, lately the budgets have been heavily criticized by practitioners (Stede, 2001; March, 1988; Neely et al. 2003) who suggested that the budgets bring more costs than benefits irrespective of the setting. The costs of budgeting did not only include the financial burden of lengthy budgetary processes but also negative influences on a company's culture resulting in undesirable or unethical behavior of the organisation members who are forced to deliver financial outcomes beyond their control (Hope \& Fraser 2003).

Due to the weaknesses in the traditional budgeting, budgeting moved to another wave, known as Better Budgeting. Better Budgeting brought forward the techniques such as Activity Based Budgeting, Zero Based Budgeting, Value Based Management, Profit Planning and Rolling Budgets (Libby \& Lindsay, 2010; Neely et al., 2003). However, several weaknesses were observed with the Better Budgeting concepts. As with activity-based management studies, capacity management studies tend to have a product-costing focus, leaving issues of capacity management integration with budgeting and other organizational practices unaddressed (Hansen et al., 2003). Even though zero-based budgeting became popular in the 1970s and 80s and proved to be a useful exercise to review discretionary overheads it was noticed in practice, the process is so bureaucratic and time consuming. Accordingly, the Better Budgeting concept too failed to address some of the fundamental issues such as linkage of the budget to the organizational strategy. Instead it promoted another level of budgeting that still 
stuck to managing numbers (Hope \& Fraser, 1997).

Much research work had been carried out about how the budgets should improve rather than how to eliminate the budgets until Hope and Fraser (1997) did the initial research work on Beyond Budgeting. Since then, several investigators including Waal (2005), Wallander (1999), Hope et al. (2011), Dugdale and Lyne (2004) have carried out research on the Beyond Budgeting concept.

With the insufficiencies of Better Budgeting, Hope and Fraser (1999) saw a growing dissatisfaction across the whole business community with the general management approach, which is based on and much influenced by traditional budgeting as well as the pervasive budgeting culture with all its negative implications for successful enterprise management. They pioneered the concept of Beyond Budgeting as a solution (Daum, 2002). Beyond Budgeting is a framework for budgeting which comprises of 6 leadership principles and 6 process principles that emphasize on employee empowerment, customer focus, competition, relative targets and team performance (Hope \& Fraser, 2003; Waal, 2005). According to Waal (2005) the 'leadership' principles support greater devolution of responsibility to teams accountable for improving customer outcomes relative to peers and competitors. The six beyond-budgeting leadership principles are described briefly underneath.

- A self-governance framework - In the beyond-budgeting organisation the hierarchical organisational structure is subdivided into smaller, self-managing units. The traditional central control system with many rules and procedures is thus abandoned. Managers have the authority to run their unit as they see fit.

- Empowered managers - Organisational members have the freedom and opportunity to act at their own discretion. There are no tight controls that restrict people in their room to manoeuvre. Managers of self-managing units act within the values and strategic boundaries as set by senior management.

- Accountability for dynamic outcomes - People in the beyond-budgeting organization are responsible for achieving competitive results, not for achieving pre-set targets for a department or function.

- Network organization - The beyond-budgeting organisation is structured in such a way that self-managing units form independent, customer-focused entities. These entities focus completely on the market and delivering value to customers.

- Market coordination - Services from central support units (like HRM, ICT) can be purchased by the self-managing units on the basis of service level agreements. Each unit can decide for itself whether it wants to use services from central support or whether it wants to hire external support.

- Supportive leadership - The organisational members are encouraged to achieve stretching goals and coached by senior managers in obtaining these. The managers of self-managing units are allowed to take risks and make mistakes, without directly being punished for it.

According to Waal (2005) the 'process' principles support adaptive management processes that enable enterprises to be more responsive to their competitive environment and customer needs. The six beyond-budgeting process principles are briefly explained below.

- Relative targets - The organisation's strategy is aimed at beating the competition, not last year's budget. The targets are set in relation to the organisation's main competitors or comparable organisations.

- Continuous strategy-setting - The strategy-setting process in the beyond-budgeting organisation is a continuous and bottom-up process, not a yearly top-down exercise. The strategy is continually adapted to the circumstances, based upon signals and input from the organisation's front line.

- Anticipatory systems - At least once every quarter managers make rolling forecasts which extend beyond year end (preferably six quarters ahead) for both the financial and non-financial critical success factors of the enterprise. There is no connection between the forecasts and the reward system, as a result of which forecasts can be set in an objective way.

- Resources on demand - Managers allocate resources to those units where they are needed most, at the time they are needed most. The self-managing units decide for themselves how much resources they need to satisfy the demands of their markets and make investment plans accordingly.

- Fast, distributed information - Information is quickly available and easy to access for those who need it in the organisation, at the time they need it. The information is not over-detailed and contains both lagging and leading indicators. 
- Relative team rewards - The rewards are based on the results of the self-managing units and the organisation as a whole, in comparison with the competition.

The success of Beyond Budgeting has been proven in several studies (Waal, 2005; Ostergren \& Stensaker, 2011) In 1998 a group of companies, mainly European (including Handelsbanken, Borealis and Volvo Cars), launched a joint-research: The Beyond Budgeting Round Table (BBRT), led by Jeremy Hope and Robin Fraser. The aim was to identify companies that scrapped their budgets, to generate best practices and case scenarios and to share the knowledge. The research showed that all the companies that have abandoned budgeting have all outperformed their direct competitors on every possible measure (both financial and non-financial), and that none of the managers of the Beyond Budgeting companies interviewed for the research desired to come back to an old budgeting model (Paludgnach, 2002).

Hope and Fraser (2003) emphasized the need to eliminate the budget; however, Frow et al. (2010) argued that evidence from their study based on "Astoria" demonstrates that the abandonment of budgeting is not the only, or necessarily the best, option for organisations to pursue. Simons $(1991,1994)$ on the other hand, suggested that the solution is not to abandon traditional management control systems, but rather to use them as part of a more extensive control package, where they may be deployed diagnostically, in association with other forms of control to ensure that important goals are being achieved efficiently and effectively.

There are ample of studies carried out on the weaknesses of traditional budgeting (Rickards 2008, Hansen et al., 2003, Bourne et al., 2003; Ekholm \& Wallin, 2000). However, Dugdale and Lyne (2004) have indicated that 71.8\% of the managers of South West England believe that the budgets are extremely important for planning, controlling and motivation. In addition, they found that only $28 \%$ of the European automobile supplying companies have implemented Beyond Budgeting while $93 \%$ of them practiced traditional budgeting.

It was also noted that the research that has been carried out focusing how certain organisations have moved to the Beyond Budgeting concept, has left several knowledge gaps. Some of the research works are merely quantitative studies and have not carried out an in-depth analysis and some are based on a single case study. A multiple case study has not been carried out by any investigator. Studies by Hope and Fraser (2003) and Wallander (1999) on Svenska Handelsbanken have not revealed what barriers existed in moving to Beyond Budgeting. Waal (2005) investigated what pre-conditions should be there to introduce Beyond Budgeting and how the Beyond Budgeting Entry Scan can be used to introduce Beyond Budgeting. However, it has not been revealed why some organisations are still lagging behind in terms of the implementation of Beyond Budgeting.

Therefore, to further investigate such knowledge gaps and contradicting views, this paper intends to identify how the budgeting practice is designed in the selected organisations; how far does the existing organizational setup support the implementation of Beyond Budgeting and why some organisations are still lagging behind, and why can or cannot the selected organisations move to Beyond Budgeting. Therefore, the research covers a wider scope that has insufficiently been covered by the prior research work.

\section{Case Study Companies}

Four leading, reputed companies which are believed to have robust management accounting practices were selected from three different industries based on the convenience of accessing personnel who are involved in the budget setting process. The management of those companies wished their companies to remain anonymous therefore the four companies are code-named as Muffler, Carol, LFC and Brown.

Muffler is a leading apparel manufacturer and exporter established over 25 years ago with a turnover exceeding USD1.8bn as of 2017. Muffler has 38 world-class apparel facilities spread over ten countries including USA, Brazil, United Kingdom, Italy, Germany and China. Muffler provides employment to over 55,000 people. The company has a lean manufacturing system that is based on the Toyota Production system. The company is well renowned for its corporate social responsibility initiatives which improve and sustain employee and community livelihoods.

Carol is leading diversified group of businesses with a history of more than 150 years. Its main lines of business are in oil palm plantations, oils and fats, beverages, investments holdings, management services, real estate and leisure sectors. The company is listed on the Colombo Stock Exchange and has a market capitalization of LKR 32bn in 2017 (Annual Report 2017) which places it among the top 5 listed companies in Sri Lanka in terms of market capitalization.

LFC is one of the largest premier licensed finance companies in Sri Lanka with a market capitalization of LKR44bn which places it among the top 20 largest listed companies in Sri Lanka in terms of market capitalization. LFC initially was a leasing company, however, now is moving to the concept of a conglomerate 
by diversifying its operations. The company highly concentrated on providing financial services and has operations in renewable energy, leisure, plantations, trading and constructions. LFC has one of the largest distribution networks compared to its peers comprising 183 branches.

Brown is a leading apparel manufacturer and exporter specialized in casual wear and lingerie manufacturing. The company employs over 40,000 and has over 42 manufacturing locations in Sri Lanka with operations in India and Bangladesh. The net sales exceeded USD $1465 \mathrm{mn}$ in 2017. The company made a revolutionary development in the apparel industry by its "Apparel City" which brings alive the 'Fiber to Store' concept. This fully fledged industrial city, complete with water, power, labour, communications and transportation is expected to provide "Plug \& Play Infrastructure" where investors can simply set up shop immediately. The company is well known for its waste management and clean technology.

\section{Methodology}

To investigate the research issue, a multiple case study approach was adopted (Yin, 2003). Case studies enable the researcher to explore and study a variety of phenomena through detailed and deep insights, with much consideration given to qualitative data gathered from many actors in individual case sites (Kodama, 2003). As stated by Yin (2003) a major strength of the case study is the opportunity to use multiple sources of evidence, with data needing to converge in a triangulation fashion, and as another result. The research question in this study is "why some organisations are still lagging behind in terms of the implementation of Beyond Budgeting?" The research question intends to find out how far the organizational set-ups support Beyond Budgeting and why they can or cannot move to Beyond Budgeting. Yin (2003) argues that "how" and "why" questions are more explanatory and likely to lead to the use of case studies, histories and experiments as research strategies. Objectives of this study also tried to identify the existing situation and evaluate the possibility of moving to Beyond Budgeting rather than identifying relationships among variables. Therefore, the case study approach seemed the most appropriate method for this study.

Moreover, steps were taken appropriately to establish the reliability and validity of the research findings by applying data triangulation. Patton (1987) discusses four types of triangulation in doing evaluations; data triangulation, investigator triangulation, theory triangulation, and methodological triangulation. This study used the data triangulation method and it encourage the investigator to collect information from multiple sources within a single study but aimed at corroborating the same fact or phenomenon. Data triangulation can assist a researcher to take advantage of the strong points of each type of data, cross-check data collected by each method, and collect information that is available only through particular techniques (Hoque, 2006).

During the data gathering process, data were collected through review of documents, interviews with top and middle level managers. All the interviewees were either directly involved in the budget setting process of the companies or had a very good understanding of the management accounting practices of the organisation. All the interviews were semi-structured interviews and were based on a pre-set interview protocol. The interview protocol was updated as the interviews progressed from one person to the next person and also from one company to another company. Interviews were limited to a maximum of one-and-half hours and certain executives could be followed up for more details. In addition to face to face interviews, data was gathered through several follow-up telephone interviews. All the interviews were voice recorded with the permission of the respective interviewees. These voice records were subsequently transcribed.

In Muffler, the Financial Controller and one of the Finance Executives were interviewed. The interview with the Financial Controller was limited to one hour; however, the Finance Executive could be followed up for information several times. Since Muffler is a leading apparel exporter several industry publications and news articles along with company website could be referred for the verification of data. In LFC, first an Assistant Manager was interviewed with the ability to follow up on information. Then the Finance Manager and Executive Director could be contacted to verify some of the information. The interview with the Assistant Manager took one-and-half hours whereas the interviews with the Finance Manager and Executive Director were limited to thirty minutes each. LFC is a leading finance company which is listed therefore most of the information could be verified through the annual report, company website and industry publications. Carol provided the opportunity to interview the Finance Manager which ran for one and half hours. However, since Carol is a leading diversified conglomerate which is listed the annual reports and published data were available to be retrieved. Brown provided the opportunity to interview one Assistant Manager and Finance Executive which were set up as one-hour interviews with each person. Brown too is a leading apparel manufacturer and exporter and several publications, and the company website was helpful in gathering and verifying data. 


\section{Discussion and Findings}

The main focus of this section is to discuss the findings of the study with respect to the research objectives. This study investigates how far the existing organizational setups support for Beyond Budgeting and explores why can or cannot these organisations move to Beyond Budgeting.

The following section elaborates the findings of each objective under each case company.

\subsection{Identification of Budgeting Practices in Case Companies}

The first objective of this study is to identify how the budgeting practices are designed in case companies. Accordingly, under each case company findings of the first objective were discussed.

\subsubsection{Muffler}

The entire budget setting process of Muffler is a zero-based budgeting approach. Muffler's budgeting process is an annually carried out process. Currently at Muffler a central budget is not imposed on individual Strategy Business Units (SBUs). Instead they prepare their own budgets aligned to achieve the corporate objectives. The budget prepared by individual SBUs would be reviewed centrally by the corporate head office finance unit and as advised changes maybe requested for the SBUs to be made to the budget. The overall responsibility of preparing budgets lies with Finance Director. However, Directors of other functions such as marketing, manufacturing and support services are responsible to complete their respective budgets accurately and support the Finance Director in meeting the deadlines.

\subsubsection{Carol}

The budgeting process of Carol takes mostly a top down approach initiated by the head office. The business unit makes its own budget and then communicates to the central planning unit who collates the budgets of all the departments. However, the targets for the business units are given by the head office - all the business units have to stick to those targets and prepare their own budgets. The Finance Manager stated that:

"Although the business units are allowed to prepare their own budgets, all the targets are still given by the Head Office."

The forecasts for the budgets are still based on the past year's data and involve a great amount of judgment by the experience of the mangers. A percentage will be adjusted to the past year's budget in order to arrive at the estimates for this year.

\subsubsection{LFC}

The budget setting process of LFC takes the form of a zero-based budgeting approach. The budget setting process starts with the target setting which is determined by the Managing Director (MD) and the Deputy Chairman (DC). They will set the execution targets for the existing year and it will be allocated to the business units. There are several business units of LFC - a micro finance unit, a factoring unit, two finance companies and an Islamic business unit. The Managers or the Chief Executive Officers of each of the business unit will have some freedom to determine their budget. However, there will be a great level of negotiation in terms of allocating resources. Finance Managers commented:

"Each of the mangers can decide how much targets they can achieve but if they are taking too easy targets the MD and the DC will push them to make the targets more realistic."

During the interviews the Executive Director of the company further contributed this idea that the business units are given autonomy to determine the level of targets they can achieve. Further the Finance Manager explained that although a zero-based budgeting approach is followed, certain items still depend on the last year's actual figures. He explained it as follows:

"Other income and expenses are very difficult to be forecasted with a zero base. Therefore, the last year's figures are considered when forecasting the other income and expenses."

Further the budget is reviewed every 6 months and monitored but does not roll its forecasts.

\subsubsection{Brown}

The budgeting process of Brown is a zero-based budgeting approach which is not based on the past year's budget but rather based on the market trends and the futuristic forecasts. The budget setting process takes approximately 3-4 months and is a mix of a bottom up and a top down approach. Brown has approximately 40 SBUs and each of the SBU is driven by the ROI and net margin. However, there is an involvement of the Corporate Office in setting the targets as well as controlling and monitoring the targets. The Finance Manager 
explained that each of the SBU need to send the budgets they prepare to the Corporate Office and on time delivery is a key performance indicator for all the SBUs. Once the SBU budgets are collated by the Corporate Office the consolidated budget is presented to the Board of Directors. The budget setting is carried out once a year; however, there are budget reviews once in every quarter. Brown does not roll its forecasts and only review the budget.

Based on the individual case study findings, it can be summarized that three companies - LFC, a service organisation and Muffler and Brown which are manufacturing organisations were following a zero-based budgeting approach in setting their budgets. Carol who is a leading diversified conglomerate seemed to follow rather a traditional and incremental approach. Accordingly, it can be concluded that except one organisation all the other case companies have already moved to the Better Budgeting concept.

\subsection{How Far the Existing Organizational Setup Supports the Beyond Budgeting Concept}

The second objective of this study is to find how far the existing organizational setup supports the Beyond Budgeting concept. For this purpose, the Beyond Budgeting principles depicted by Hope and Fraser (2003) were used. The following section elaborates the evidence of each case company on how existing organizational setup supports the Beyond Budgeting concept.

\subsubsection{Muffler}

Muffler has a personalized lean manufacturing system based on the Toyota Production System. The lean operating system emphasizes on maximization of resources utilization with the objective of becoming responsive to customer demand, provide value for money solutions from design to delivery.

During the interviews the Financial Controller of Muffler explained that the entire budgeting process of Muffler is based on zero based budgeting approach. Costs have to be justified by the individual mangers who act as drivers for costs and past year's costs are considered to be irrelevant. This, to an extent reflects the continuous strategy setting approach which is a feature of a Beyond Budgeting organisation as described by Hope and Fraser (2003).

According to the financial controller, Muffler practices a life cycle costing approach for the long-term assets. He explained that cash flows for the entire life span of the projects are considered and appropriate investment techniques applied thereby applying the principles of life cycle costing. Only if the payback and ROI are satisfactory such projects will proceed. This feature is reflective of a "resources on demand" approach which encourages having no fixed investment budget (Hope \& Fraser, 2003) but justifying the investment requirement through a long-term vision.

At Muffler a participative approach of budgeting is used whereby finance department does not enforce the budget to department/units and the budget is prepared in collaborative effort with the drivers of the cost. Finance executive states that:

"For example, the production team will actively participate in setting the production budget for the plant. The departments and business units have the freedom to govern themselves as long as they align with the corporate strategy."

The participative, self-governing approach with limited head office involvement reflects the self-governance principle of a Beyond Budgeting organisation (Hope \& Fraser, 2003).

Employee empowerment (Hope \& Fraser, 2003) was a clearly visible feature in Muffler. The "Go Beyond" program launched by Muffler in 2003 mainly focused empowering female employees who constitute $93 \%$ of the employee carder. Also, Muffler's managers are given autonomy in decision making and are not always restricted to budgeted number. This was further explained by the Financial Controller:

"If certain strategies deviate from that of the budget and it can be proven that it was done in the best interests of the organisation and the Board of Directors usually supports such initiatives."

The supportive leadership as explained by Hope and Fraser (2003) was visible in Muffler. According to the Finance Manager, in the budgeting process, the final outcome is presented to the Board of Directors. During this presentation the Board of Directors consider a holistic view of the company's future state and not only depict numbers and figures but also provide advice on areas covering customer and brand strategy; manufacturing strategy; support service function strategies; lean manufacturing approaches and research and innovation policies.

The fast-distributed information (Hope \& Fraser 2003) were visible in Muffler as it depends highly on the IT systems, such as its well-established ERP solution and SAP, which provides management with real time 
comprehensive information for decision making. According to the Finance Executive, internal communication is mainly done through emails, where each user is given a Muffler-specific email address. Overall the IT systems support the smooth flow of information across the division.

The targets being dynamic and the managers being recognized for dynamic outcomes (Hope \& Fraser 2003) was another Beyond Budgeting principle visible in Muffler. During the recession that prevailed in 2008, Muffler's managers were not "punished" or "forced" to achieve certain targets but other ways and means of cutting down the costs were practiced. The budgetary system not being rigid and the outcomes being accepted to a certain dynamic level was a positive feature in Muffler.

The customer focus, at both internal and external level is visible at Muffler. Muffler is a key supplier to a number of top global apparel, sportswear and lingerie brands and has maintained strong customer relationships over fifteen years. The customer focus is a feature that would support Muffler to move to Beyond Budgeting as customer focus encourages networking the organisation to accommodate adaptive management (Hope et al., 2011). This was further verified by the Financial Controller:

"Muffler is one of the organisations who practice the customer orientation at its best in this industry....that has been one of the critical success factors of the organization."

\subsubsection{Carol}

A certain level of decentralized and self-managing units was visible in Carol which supports the self-governance feature of a Beyond Budgeting organisation. The organisation consists of many business units - leisure, brewery, real estate, management services, financial services and plantations all of which are decentralized to a certain extent and autonomy is provided to operate as profit-centers which should be self-sustaining. The Finance Manager of Carol mentioned that:

"Most of the SBUs are profit centers and are driven by their net margin."

This is similar to the situation at Svenska Handelsbanken who set ROI as their performance measure for each of the branches (Hope \& Fraser 2003).

Customer focus was a feature that was visible in Carol too. Carol has successfully maintained long standing customer relationships with corporate, retail and wholesale customers lasting over 10 years. High customer focus was visible in Ahlsell, Volvo and several other companies that adapted a Beyond Budgeting model (Hope \& Fraser 2003).

The participative contribution of the business units in the budget setting process is a feature that would support Carol to move to Beyond Budgeting.

Carol has fast information flows which are backed by robust IT systems. The Finance Manager explained that the management reports can be effectively generated through the existing information system despite some of the databases having to be maintained on MS Excel sheets. The information is accessible to the users with password protection and hence the communication is safe and authorized.

\subsubsection{LFC}

The empowered managers and the accountability for dynamic outcomes which are key principles of Beyond Budgeting (Hope \& Fraser 2003) were visible at LFC to a great extent. One of the Managers explained that the managers are not strictly evaluated by the budget and have the freedom to be innovative and go beyond the budget. The budget was merely a reporting requirement for LFC and the organisation was managed with an entrepreneurial spirit by its top management. Therefore, moving to a budget free system was not seen as a surprise for LFC. This was further explained by the Executive Director:

"We always encourage managers to be innovative and do not manage our organization based on numbers. If managers can justify what they have achieved given the business conditions, it is well-received by the top management. That has been a reason for the fast growth we have achieved."

LFC was seen to be a continuously strategy setting organisation which is indicated in their numerous innovative new products of the recent years. Continuous strategy setting which encourages the organisation to be responsive to the environment and be innovative especially allowing the strategy to emerge from bottom-up level is a key principle of Beyond Budgeting (Hope \& Fraser 2003). The Executive Director explained that some of the key new products emerged from the views of the marketing or sales people. The annual report of the company further verified this as: 
"This year we initiate the gold cheque discounting which is a timely solution to SME borrowers to suit their needs. Our agility and flexibility are made possible entirely by our talented and dedicated people."

Hope and Fraser (2003) explained that a Beyond Budgeting organisation needs to be setting targets relative to the market and the competitor. The Assistant Manager mentioned that LFC is highly competitive and the target setting at the top management level is carried out by considering the competitor action. The Executive Director further confirmed this view.

"We set our portfolio growth and profit targets by looking at the competitors. Currently we are the number one Finance Company in the country, but we always look at the market and the competition when setting our portfolio growth and profit targets."

Customer focus was a feature that was visible in LFC to a great extent. The Assistant Manager explained that:

"Some of our micro financing and the Islamic financing products are highly customized to suit the attitudes and the culture of the customer. We cater to customers who feel shy and insecure to walk into a sophisticated bank through our post offices."

This was further confirmed in the company annual report as:

"We helped to revolutionize the small and medium sector by financing assets that were self-financing for the customers. Our channel mechanism comprising post offices offer excellent service to the otherwise untapped micro clientele."

Strong leadership (Bogsnes, 2016) was another feature of Beyond Budgeting that was clearly visible in LFC. One of the Managers mentioned that LFC is being managed by the well-known, prominent entrepreneurs who hold a strong track record of achievements and leadership initiatives.

\subsubsection{Brown}

Similar to Muffler, customer focus was a feature that was clearly visible in Brown too. Customer focus is a feature that supports an organisation to become a network organisation which is a principle of Beyond Budgeting (Hope and Fraser 2003). The Assistant Manager of Brown explained that before designing a pattern for clothing, all the customer requirements are properly gathered and documented, and certain cost reduction techniques are agreed upon. This customer focus was clearly mentioned in a statement made by the CEO to Tukatech (2012).

"Cost alone is not our focus. We want to provide speed and value to our customers."

Relative target setting was a principle of Beyond Budgeting (Hope \& Fraser 2003) that could be seen at Brown. Brown is highly competitor focused in contrast to Muffler and sets its targets relative to the competitors. The Assistant Manager mentioned that Brown has a "Market Watch" which collects competitor information and process them for the decision making by the top management. Also, the Assistant Manager mentioned that most of the social responsibility and community work is carried out as a result of this competitor focus.

"Most of Brown's top global apparel buyers such as Gap, Banana Republic and Marks \& Spencer refuse to buy from so-called garments with guilt. Therefore, to stay ahead of the competition we need to prove that we are engaged in community services and ethical work practices."

Resources on demand were also a feature that was visible in Brown to a great extent. According to the Assistant Manager, the resources are allocated based on the need and each business unit can justify their resource requirement. This was further verified by the environmental strategy of Brown which ensures that resource allocation is done based on the priority of the environment and not on the last year's budget.

Empowering employees to be innovative and team rewards and team work were clearly visible features in Brown (Hope \& Fraser 2003). The Finance Executive mentioned that team performance has a great weight on the performance evaluation and certain projects and assignments are purely based on the achievement of objectives through team effort. Also, he explained that teams are free to come up with innovative ideas which are welcomed by the top management. This was further verified by having "teamwork" and "learning and development" as core values of the organisation on the Brown value statement which mentioned that:

"Brown provides a collaborative team environment that would promote ideas, risk taking and creativity. We will not take the personal glory at the expense of our team and will take individual responsibilities for achieving team goals."

It was noted that Brown encourages strategy to emerge through its employees. The Assistant Manager mentioned that Brown practices an "open door" policy. 
"Any employee can reach even the highest level of Brown and bring up any new idea. Even the machine operator can come up with something new and approach anyone in the organisation."

This was indicative of the continuous strategy setting feature that is visible in a Beyond Budgeting organisation. In addition, there is an award program designed to award the innovative thinking very well confirms above views.

Strong leadership was clearly visible at Brown as the Assistant Manager mentioned that Brown is managed by the nationally recognized management professionals. The company profile indicates that the CEO of Brown was instrumental in the establishment of The Joint Apparel Association Forum (JAAF) - the apex body of the apparel industry primarily involved in driving strategy for the industry. In addition, another Director of Brown within a year after joining Brown began to successfully manage and develop a growing number of subsidiaries under the emerging Brown Group.

Fast distributed information (Hope \& Fraser 2003) which is essential for the Beyond Budgeting organisation could be seen at Brown. The Assistant Manager of Brown mentioned that:

"Brown is well networked with email and internet access to staff. Even the factory staff has proper communications systems such as signal boards which are easily understood by them."

This was further explained by the Finance Executive who explained that the formal communication systems are well backed by the IT department. In addition, weekly and monthly meetings are being carried out on assigned tasks to keep everyone in the team aware of the ongoing work.

Based on the findings it can be concluded that the six principles namely self-governance framework, empowered employees, customer focus, supportive leadership, continuous strategy setting, and fast distributed information are strongly present in most of the organisations. Out of these six principles the first four are "leadership principles" of Beyond Budgeting. In addition to the above principles, accountability for dynamic outcomes, relative targets and resources on demand could be seen in at least two organisations. Therefore, it can clearly be concluded that in the existing organizational setups, leadership principles strongly support the Beyond Budgeting concept (Bogsnes, 2016) compared to "process principles", hence the process principles are what need to be improved.

\subsection{Identification of why can or cannot the Organisations Move to Beyond Budgeting}

The third research objective intended to identify why can or cannot the organisations move to Beyond Budgeting. The following section elaborates the evidence of each case company in relation to the objective three.

\subsubsection{Muffler}

According to the Finance Executive, Muffler's individual employee performance evaluation takes team performance into consideration during appraisals. There is a considerable weight given to teaming in the employee performance evaluation scheme.

In a Beyond Budgeting organisation the performance of other comparable teams is taken into consideration at a broader level (Hope \& Fraser 2003). But in Muffler it is different, and the Finance Executive explained it in the following way:

"The main barrier to set relative team rewards was that each of the SBUs has different operating conditions therefore an inter-SBU comparison may result in demotivation."

Setting relative targets compared to the competitor was seen to be a challenging task when setting the competitive strategy of Muffler. Benchmarking was visible in Muffler to a great extent as it was adapting many international best practices in apparel manufacturing. However, benchmarking with the competitor was identified to be at a poor level mainly because information about the competitor was hard to be found. The Financial Controller of Muffler mentioned:

"There are very few major competitors who are not listed...therefore obtaining information about the competitor strategy is a challenging task. Also, we are already the leading player in the market and we believe that we stay ahead of the competitor rather than following the competitor. Therefore, we do not consider competition as a serious issue when it comes to budget setting."

Muffler does not roll its budgets frequently. The budget period is divided into monthly "monitoring periods" but rolling the forecasts considering the market conditions does not happen at Muffler. The likely reason given by the Finance Executive was that it consumes a large amount of time and effort to roll the forecasts and make a new budget. It was suggested that: 
"If we have sophisticated software to support making adjustments it would be easier. But at the moment we have a lot of manual work to do on MS Excel."

This is a barrier to change the organisation into an adaptive and an anticipatory system as explained by Hope and Fraser (2003).

The market coordination feature which challenges the shared services in an organisation and provides autonomy for the business units to purchase what they need (Waal, 2005) is a principle of Beyond Budgeting which was found to be absent in Muffler. The Financial Controller of Muffler mentioned that the main barrier to eliminate the shared services such as HR and IT is that the employees are very much used to depending on the shared services over a period of time and the need to control certain common resources. Due to that the shared services having a higher demand there are inefficiencies and delays in delivering the output. This was further clarified by the Finance Executive who mentioned that:

"Sometimes it is difficult to get the stationary ordered or a computer fixed, as we are always depending on the shared services to do it for us. They also get number of requests a day and therefore delays and inefficiencies are unavoidable."

According to the Financial Controller, to a great extent budgets do drive Muffler's managers to achieve targets as mostly their performance. Further, the achievement of the budget is important because manager's incentives would be dependent on achievement of budgets. As such planning and control based on budgeted numbers is critical for performance measurement and evaluation. From the perspective of the Financial Controller, this dependency on budget is one barrier that Muffler cannot completely eliminate the budget. The Financial Controller also mentioned that the budgets provide a guidance to some extent and eliminating budgets cannot be done overnight.

\subsubsection{Carol}

The managers of Carol lacked empowerment to take risks and make mistakes as they were strictly controlled by the budget. The performance bonuses of Carol's managers are tied to the achievement of the budget while not achieving the budgets costs the job to certain managers. The Finance Manager of Carol explained:

"I can remember there were occasions that some of the senior managers were asked to go home where they could not achieve the budget targets - because budget target achievement is of such importance."

Empowerment is an important feature in a Beyond Budgeting organisation (Hope \& Fraser 2003) and lack of empowerment remains a key barrier for Beyond Budgeting implementation. From the perspective of the Finance Manager, the organisation is accustomed to achieving budget targets and it is known as a golden rule in performance evaluation. This dependency culture on budgets for performance evaluation can be seen as the barrier to empower the managers. In addition, the Finance Manager mentioned that:

"It is difficult to empower people at time because of lack of virtues. You cannot expect everyone to act responsibly and transparent."

Dynamic outcomes were not recognized as acceptable at Carol as achieving the budget target is a crucial responsibility of a manager. However, exceptionally good performance was recognized and rewarded, yet adverse variances were not treated as acceptable. From the perspective of the Finance Manager to justify the adverse outcomes the top management needs to change their views on realistic targets. The Finance Manager mentioned that:

"The budgets have to be achieved, it's true; but also, the budgets should be realistic to achieve. If your budget target is going to change all the time it would not be realistic to achieve it because the goal is ambiguous."

Continuous strategy setting seemed to be a feature that is blocked by the bureaucracy and the fear in employees. According to the Finance Manager the employees rarely bring up new ideas to the top management straight forward and many good ideas seem to be dying at the middle layer of the management. The Finance Manager of Carol explained that:

"Although there are no restrictions to bring up your suggestions to the top management, people are generally scared to approach the top management straight. As I see, this is an established organisation and the bureaucracy is unavoidable to some extent."

According to Waal (2005) the continuous strategy setting is possible in an organisation if there is a bottom up approach for strategy setting. 
Carol too did not seem to be rolling its forecasts. The Finance Manager explained that the budget is monitored quarterly for control purposes. However, rolling the forecasts are not done because of the following reasons mentioned at the interviews:

"Making the annual budget itself is a rigorous, time-consuming process. Rolling the forecasts may take even more time and resources and end up with not-so-reliable forecasts."

The above views are mostly cited in previous research work carried out by Hope et al. (2011) and Dugdale and Lyne (2004). Hope et al. (2011) mentioned that as neutralized by the powerful antibodies of the budgeting immune system. Budgeting, perhaps more than any other process defines the cultural norms inside an organisation. It was found that Carol's managers had the autonomy to decide which resources it should acquire. However, they had to go through the central shared service process which was time consuming and lacked market coordination. Market coordination is one principle of Beyond Budgeting (Hope \& Fraser 2003). The Finance Manager of Carol mentioned that although it's time consuming and bureaucratic, shared services are needed to have a control on acquiring resources. The Finance Manager viewed:

"Eliminating shared services is an impossible task as much of the paperwork and coordination support is provided by the shared services. It is a too much of a burden for an individual business unit to focus attention on those HR, IT and such shared services."

Setting relative targets seems to be a challenge for Carol too. Carol practices a benchmarking approach when adapting some of its manufacturing, brewery and hotel management practices. The actions of the competitor and the market conditions are incorporated to some extent in target setting by the Corporate Office. However, Carol is a leading diversified conglomerate and operates in many business lines including beverage, financial services, management services, leisure, plantation and real estate and conducts operation overseas too. Therefore identifying a realistic competitor itself is a challenge which is the main barrier to set relative targets. The Finance Manager of Carol viewed:

"Setting targets relative to a competitor is complicated as we operate in many business lines. Each business line will have a different competitor and you will have to consider each business line separately."

\subsubsection{LFC}

LFC was seen to be decentralized organizations; however, the self-governance framework that is a key principle of Beyond Budgeting (Hope and Fraser 2003) was not strongly present as almost all the business units highly depend on the Parent Company which the key decision is making unit. According to the Executive Director, LFC is decentralized to a great extent as the business units operate on their own and the CEOs are free to make decisions on their own. However, the Executive Director also mentioned that:

"The individual business units need to align with the Corporate Strategy and therefore cannot be considered as fully independent. The Board of Directors can always over-write the decisions of the CEOs which frequently happen."

As the reason for the disability to make all business units completely independent the Executive Director explained that:

"We need to align with one policy for the whole Group and cannot have different policies which arouse conflict of where we should reach as an organization."

Accordingly, decentralization was viewed by LFC as be giving rise to ambiguous goals. This idea was clearly mentioned in the company's annual report:

"By aligning its business interests with the sectors, LFC has placed itself on a strong upward trajectory that grows steeper."

The market coordination and resources on demand are two important principles of Beyond Budgeting (Hope \& Fraser 2003) which was seen to be hard to implement at LFC. According to the Assistant Manager LFC highly depend on shared services such as HR, marketing and was seen to be difficult to be eliminated. This was clearly stated in the company's annual report in the following way:

"As the Group began to expand, the Board reviewed the operations and a decision was taken to centralize support services. This ensured that the procedures and controls were standardized across all Group companies."

As a reason the Executive Director explained that the shared services have proven to be efficient in providing 
them which provides a shared platform for "learning through mistakes". The company annual report further verified this idea as:

"The Group companies should share lessons learnt and experiences and immediately commence operations at a high level rather than go through repetitive cycles of leering."

However, due to the high dependency on the shared services, the resources were seen to be not flowing on demand, rather it has been based on a standardized resource allocation policy of the shared service unit. According to the Assistant Manager there are process change requests from IT division which are pending surprisingly more than two years. By the time the process change request is completed the environment has changed and the request is outdated.

In addition, rolling the forecasts every month was seen as creating extra work by the Assistant Manager. Currently only the budget monitoring is carried out every 6 months and rolling the forecast is not done. The main barrier to implement the rolling forecast was not having a robust information system. From the point of view of the Assistant Manager:

"We have an in-built IT system and some of the information cannot be generated automatically. There have been situations where the IT system has generated incomplete inaccurate data. Because of that first the IT system need to be upgraded to accommodate the rolling forecasts."

Setting relative team rewards was seen to be a challenging task for LFC. The Assistant Manager explained that:

"Measuring team effort is somewhat tricky. People always do not work for the best interest of the team and the person with the team spirit can be unfairly treated if team performance is rewarded."

This view was further explained by the Executive Director who mentioned that the employees need to have teaming skills. However, in rewarding them the individual contribution should be separately considered to encourage competition.

\subsubsection{Brown}

At Brown, budgets seemed to be providing guidance to mangers on what direction to move. The Assistant Manager explained that:

"It is based on the budget that the CEOs of particular business units know how well they should do in the next year."

From the perspective of the Assistant Manager of Brown's manager performance evaluation had a significant weight on achieving the budgeted ROI or net margin. The dependency on budgets to evaluate performance was seen to be a barrier to eliminate the budget. The Assistant Manager explained that:

"If budgets are eliminated it is difficult to monitor the performance by the Corporate Office. The Board of Directors evaluates the performance and monitors and control the CEOs of each SBU based on the ROI and the net margin achieved by them compared to the budget."

This view was further explained by the Finance Executive who mentioned that achieving the budget target is important for managers. This is further confirmed by the findings of Dugdale and Lyne (2004) who argued that budgets still play a key role in monitoring and control.

Rolling the forecasts was seen as a good but challenging activity and arising confusion on which direction to move. The Assistant Manager explained that:

"It is a good thing to look ahead the next month and adjust the budget to include the latest information; however, obtaining information itself is a challenging task. Not only that when the targets keep on changing it is difficult to track where we will be heading to"

The Finance Executive further explained that some of the budget items are still based on past year's data and obtaining the latest market information will be a somewhat difficult task as perfect information is hardly available.

According to third objective, to identify why can or cannot the organisations move to Beyond Budgeting, findings of four companies can be summarized as follows. Both Muffler and Brown indicated eight of the twelve principles of Beyond Budgeting while LFC indicated six of the Beyond Budgeting principles. Carol indicated only four of the principles of Beyond Budgeting. Accordingly, Carol seemed to indicate most of the barriers of moving to Beyond Budgeting. However, it was not only Carol that indicated barriers of Moving to Beyond Budgeting. Muffler, LFC and Brown also had certain concerns of being a budget-free organisation. 
Except LFC none of the organisations was sufficiently aware of a concept where the budgets can be totally eliminated. None of the four organisations rolled its budgets due to the complications and extra work which were perceived to be a burden. The shared services seemed to be hard to eliminate due to the high dependency culture on shared services. Also, in all organisations except LFC there was a high dependency on budgets to evaluate manager performance and provide guidance and direction. Brown, Carol and LFC viewed setting dynamic goals as confusing, ambiguous and creating extra burden. Carol could not identify its direct competitor while Muffler complained of difficulties of deriving competitor information to set relative targets. Carol viewed bureaucracy and lack of virtues as barriers of empowering managers. LFC viewed setting relative team rewards would be unfair as all employees do not equally contribute well to teamwork.

\section{Conclusion}

Based on the findings from four case companies it can be concluded that in the existing organizational set-ups, leadership principles of Beyond Budgeting were strongly present compared to process principles. Also, the study found that lack of awareness on Beyond Budgeting, complications of setting rolling forecasts, bureaucracy, lack of virtues, difficulties in assessing team performance, dependency culture on budgets to guide and evaluate performance, dependency culture on shared services, perceiving dynamic goals as too ambiguous to set and lack of competitor intelligence were the main barriers of moving to Beyond Budgeting. Accordingly, it can further be concluded that the organisations had certain features that supported the Beyond Budgeting concept; however, certain barriers stagnate them from completely transforming to Beyond Budgeting organisations.

\section{References}

Anthony, R. N. (1965). Planning and Control Systems: A Framework for Analysis. Harvard University Press.

Bogsnes, B. (2016). Implementing Beyond budgeting: Unlocking the Performance Potential. John Wiley \& Sons, Inc., New Jersey.

Bourne, M., Neely, A., Mills, J., \& Platts, K. (2003). Implementing performance measurement systems: a literature review. J. Business Performance Management, 5(1), 1-24.

Chong, V. K., Eggleton, R. C., \& Leong, M. K. C. (2005). The Impact of Market Competition and Budgetary Participation on Performance and Job Satisfaction. The British Accounting Review, 37(1), 115-133. https://doi.org/10.1016/j.bar.2004.06.007

Daum, J. (2002). Beyond Budgeting: A Model for Performance Management and Controlling in the 21st Century? Controlling and Finance, 5, 33-34.

Dugdale, D., \& Lyne, S. (2004). The Changing Roles of Company Budgets. Department of Economics. University of Bristol.

Ekholm, B., \& Wallin, J. (2000). Is the Annual Budget Really Dead? The European Accounting Review, 9(4), 519-539. https://doi.org/10.1080/09638180020024007

Frow, N., Marginson, D., \& Ogden, S. (2010). Continuous Budgeting: Reconciling Budget Flexibility with Budgetary Control. Accounting, Organisations and Society, 35(4), 444-461. https://doi.org/10.1016/j.aos.2009.10.003

Hansen, S. C., Otley, D. T., \& Stede, W. (2003). Practice Developments in Budgeting: An Overview and Research Perspective. Journal of Management, 15, 95-116. https://doi.org/10.2308/jmar.2003.15.1.95

Hope, J., \& Fraser, R. (1997). Beyond Budgeting: Breaking Through the Barrier to the Third Wave. Management Accounting, 75(11), 20-23.

Hope, J., \& Fraser, R. (1999). Beyond Budgeting: Building a New Management Model for the Information Age. Management Accounting, 77(1), 16-21.

Hope, J., \& Fraser, R. (2003). Beyond Budgeting: How Managers Can Break Free from Annual Performance Trap. Harvard Business School Press, Boston, MA.

Hope, J., Bunce, P., \& Roosly, F. (2011). The Leaders' Dilemma: How to Build an Empowered and Adaptive Organisation without Losing Control. John Wiley \& Sons, Ltd. USA.

Hoque, Z. (2006). Methodological Issues in Accounting Research: Theories and Methods. Spiramus Press Ltd.

Kodama, M. (2003). Strategic innovation in traditional big business: Case studies of two Japanese Companies. Organization Studies, 24(2), 235-268. https://doi.org/10.1177\%2F0170840603024002345

Libby, T., \& Lindsay, R.M. (2010). Beyond Budgeting or Budgeting Reconsidered? A Survey of North-American 
Budgeting Practice. Management Accounting Research, 21, 56-75.

https://doi.org/10.1016/j.mar.2009.10.003

March, J. G. (1988). Decisions and Organizations. Basil Blackwell.

Neely, A., Mike, B., \& Chris, A. (2003). Better Budgeting or Beyond Budgeting? Measuring Business Excellence, 7(3), 22-28. https://doi.org/10.1108/13683040310496471

Niels, S., \& Per Nikolaj, B. (2014). Beyond Budgeting and change: a case study. Journal of Accounting \& Organizational Change, 10(3), 409-423. https://doi.org/10.1108/JAOC-05-2012-0032

Ostergren, K. \& Stensaker, I. (2011). Management Control Without Budgets: A Field Study of 'Beyond Budgeting' in Practice. European Accounting Review, 20(1), 149-181. https://doi.org/10.1080/09638180903487842

Paludgnach, P. (2002). Beyond Budgeting in an International Manufacturing Company. Retrieved from http://people.arcada.fi/ eldons/Seminar\%202012/Pierre\%20Paludgnach\%20Thesis\%202.pdf

Patton, M. Q. (1987). How to use qualitative methods in evaluations. SAGE Publications.

Rickards, R. (2008). An Endless Debate: The Sense and Nonesense of Budgeting. International Journal of Productivity and Performance Management, 57(7), 569-592. https://doi.org/10.1108/17410400810904038

Simons, R. (1991). Strategic orientation and top management attention to control systems. Strategic Management Journal, 12, 49-62. https://doi.org/10.1002/smj.4250120105

Simons, R. (1994). How New Top Managers Use Control Systems as Levers of Strategic Renewal. Strategic Management Journal, 15(3), 169-189. https://doi.org/10.1002/smj.4250150301

Stede, W. (2001). The Effect of Corporate Diversification and Business Unit Strategy on the Presence of Slack in Business Unit Budgets. Accounting, Auditing and Accountability Journal, 14(1), 30-52. https://doi.org/10.1108/09513570110381060

Tukatech. (2012). Tukatech: A Case Study.

Waal, A. (2005). Is Your Organisations Ready for Beyond Budgeting? Measuring Business Excellence, 9(2), 56-67. https://doi.org/10.1108/13683040510602885

Wallander, J. (1999). Budgeting: An Unnecessary Evil. Scandinavian Journal of Management, 15(4), 405-421. https://doi.org/10.1016/S0956-5221(98)00032-3

Yin, R. K. (2003). Case Study Research-Design and Methods. 3rd Edition, Thousand Oaks, CA: Sage.

\section{Copyrights}

Copyright for this article is retained by the author(s), with first publication rights granted to the journal.

This is an open-access article distributed under the terms and conditions of the Creative Commons Attribution license (http://creativecommons.org/licenses/by/4.0/). 